\title{
Cơ sở dữ liệu lớn cho bất động sản
}

\section{Big data for Real Estate market}

\author{
Hứa Phước Lương ${ }^{1,2 *}$ \\ ${ }^{1}$ Trường Đại học Mở Thành phố Hồ Chí Minh, Việt Nam \\ ${ }^{2}$ Công ty cổ phần cơ khí xây dựng thương mại \& dịch vụ Ấnh Dương, Việt Nam \\ *Tác giả liên hệ, Email: huaphuocluong@gmail.com
}

THÔNG TIN

DOI: $10.46223 /$ HCMCOUJS. proc.vi.16.1.1851.2021

Ngày nhận: 7/3/2021

Ngày nhận lại: 31/3/2021

Duyệt đăng: 5/4/2021

\section{TÓM TẮT}

Nội dung bài viết này tìm hiểu, phân tích về việc dữ liệu lớn sẽ tác động đến việc mua, bán và phát triển bất động sản như thế nào; phân tích những tiêu chí - khó khăn - hạn chế khi lấy dữ liệu trong bất động sàn; một số khảo sát về ứng dụng của dữ liệu lớn trong doanh nghiệp bất động sản trên thế giới. Từ đó đưa ra những đề xuất và giải pháp cho việc sử dụng kết hợp giữa Dữ liệu lớn (Big Data) - Trí tuệ nhân tạp (AI) - Internet vạn vật (IOT) cho ngành bất động sản tại Việt Nam.

\section{Tù khóa:}

dữ liệu lớn (big data), trí tuệ nhân tạo (AI), internet vạn vật (IOT), công nghệ thông tin (CNTT)

\section{Keyword:}

Big Data, Internet of Things (IoT),

Artificial Intelligence (AI),

Information Technology (IT)

\section{Giới thiệu}

Các công nghệ dựa trên Dư liệu lớn có thể cung cấp những hiểu biết và cách tiếp cận mới về cách phát triển, định giá, bán và mua bất động sản. Dữ liệu lớn, lượng thông tin khổng lồ được tạo ra hàng ngày trong cuộc sống của chúng ta, đang làm thay đổi các mô hình kinh doanh trong các ngành từ tài chính đến du lịch. Nó cũng đang thâm nhập vào bất động sản, một lĩnh vực đa ngành, trị giá hàng tỷ đô la (Williams, 2020).

John D’Angelo, người lãnh đạo lĩnh vực bất động sản của Deloitte có trụ sở tại New York - Hoa Kỳ, cho biết: "Bất động sản từ trước đến nay thường đi sau trong các công cụ và công nghệ". Ngày nay, ngày càng có nhiều công ty công nghệ được thành lập, cũng như các công ty bất động sản lớn, đang bắt đầu tìm kiếm thông tin chi tiết thông qua quá trình thu thập dữ liệu lớn của các công cụ Trí tuệ nhân tạo (Williams, 2020).

Để hiểu thấu đáo về hiện tượng dữ liệu lớn đã muộn trong vài năm trở lại đây so với việc 
công nhận dữ liệu thông thường. Nghiên cứu hàn lâm liên quan cũng vậy. Trên thực tế, nó đã nhận được sự quan tâm cao của giới học thuật và công nghiệp ngay khi được trình bày, kéo theo sự bùng nổ dữ liệu lớn cả về nghiên cứu lý thuyết và ứng dụng thực tế. Các doanh nghiệp bất động sản nắm bắt cơ hội kịp thời để thực hiện thành công, mặc dù nghiên cứu có hệ thống về các ứng dụng trong dữ liệu lớn trong học thuật cho đến nay vẫn chưa đủ.

McKinsey là người đầu tiên đưa ra khái niệm về dữ liệu lớn. Dữ liệu lớn đã trở thành một yếu tố quan trọng của sản xuất thâm nhập vào các ngành công nghiệp và các lĩnh vực chức năng khác nhau ngay bây giờ. Việc khai thác và ứng dụng dữ liệu lớn đồng nghĩa với một làn sóng tăng trưởng năng suất và thặng dư tiêu dùng mới (Manyika et al., 2011). Viktor Mayer-Schönberger chăm chú vào nghiên cứu về dữ liệu lớn. Ông còn được mệnh danh là nhà tiên tri của kỷ nguyên dữ liệu lớn. Ông đã đưa ra quan điểm rằng dự đoán là cốt lõi của dữ liệu lớn. Sự chuyển đổi từ các mẫu thành dữ liệu tổng thể, sự thay đổi từ theo đuổi tính chính xác để chấp nhận sự không chắc chắn và tính tương quan thay vì quan hệ nhân quả là không thể thiếu để chuẩn bị cho thời đại dữ liệu lớn (Mayer-Schönberger \& Cukier, 2014). Ông cũng nghiên cứu cách đưa ra lựa chọn từ khối lượng dữ liệu phức tạp và sau đó là cách xây dựng một tương lai lành mạnh tích cực (Manyika et al., 2011). Tạp chí Nature đã phát hành đặc biệt về dữ liệu lớn vào đầu năm 2008, mô tả giá trị tiềm năng của dữ liệu lớn và thách thức từ các kỹ thuật xử lý dữ liệu trong công nghệ Internet, $\mathrm{y}$ sinh và khoa học môi trường, công nghệ đám mây và các lĩnh vực khác. Tương tự như vậy, "Science" một trong những tạp chí học thuật quốc tế hàng đầu, đã xuất bản một số đặc biệt để truyền đạt những ý tưởng về thời của dữ liệu lớn. Năm 2012, học viện toán học và tin học châu Âu đã nghiên cứu dữ liệu lớn một cách có hệ thống bao gồm việc quản lý dữ liệu lớn, hướng và kết quả của nghiên cứu học thuật (Li \& Xueqi, 2012). Trong lĩnh vực ứng dụng của dữ liệu lớn trong thực tế, Lohr (2012) giữ quan điểm rằng dự báo bán bất động sản cho quý tiếp theo phụ thuộc vào dữ liệu lớn chính xác hơn nhiều so với dự báo của các nhà kinh tế (Lohr, 2012). Và điều này có thể là một cú sốc đối với ý thức về quyền sở hữu dữ liệu MIIT nhấn mạnh bốn dự án đổi mới về các kỹ thuật chính bao gồm công nghệ xử lý thông tin trong kế hoạch "năm năm lần thứ mười hai" vào tháng 12 năm 2012, mặc dù "dữ liệu lớn" không phải là định nghĩa chính thức khi đó. Công nghệ xử lý thông tin như kỹ thuật lưu trữ dữ liệu khối lượng lớn và phân tích thông minh hình ảnh video có liên quan chặt chẽ đến dữ liệu lớn. Với thời đại của đám mây, dữ liệu lớn không chỉ là từ hot của CNTT mà còn là trọng tâm của nghiên cứu học thuật. Trung tâm nghiên cứu trong nước hiện nay về các lĩnh vực có lượng lớn dữ liệu dễ dàng có sẵn, chẳng hạn như hệ thống quản lý thông tin thư viện và xây dựng thư viện số, ảnh hưởng của dữ liệu lớn đến văn hóa và truyền thông, bối cảnh tiếp thị kinh doanh và kế toán với dữ liệu lớn, vi mô - quản lý tín dụng nhỏ dựa trên dữ liệu lớn, kiểm soát và phòng ngừa dịch bệnh phụ thuộc vào dữ liệu lớn, v.v. Mặc dù đã đạt được một số thành tựu, nhưng các ứng dụng của dữ liệu lớn trong một số lĩnh vực nhất định vẫn tiên tiến hơn. Ví dụ, có khá nhiều trang cổng thông tin hỗ trợ chia sẻ và giao tiếp dữ liệu lớn, trong khi nghiên cứu học thuật về tài nguyên dữ liệu lớn hoặc cách định giá các tài nguyên này còn thiếu. Và các nghiên cứu về phạm vi của các vấn đề chia sẻ dữ liệu hoặc giao dịch thì ít hơn. Tương tự, nghiên cứu hàn lâm về dữ liệu lớn của bất động sản cũng đi sau hoạt động của các nhà kinh doanh bất động sản. Xuất phát từ những lý do đó, tác giả chọn chủ đề "cơ sở dữ liệu lớn cho bất động sản" cho bài viết của mình.

\section{Hiện trạng}

Các ứng dụng hiện tại của dữ liệu lớn trong các doanh nghiệp bất động sản Trung Quốc

Về dữ liệu lớn được coi là "nguồn dầu khí trong tương lai” (Li \& Xueqi, 2012). Ở cấp độ công nghiệp, thời đại dữ liệu lớn có khả năng mang lại không gian phát triển lớn hơn cho những doanh nghiệp có số lượng dữ liệu khổng lồ và các kỹ thuật xử lý dữ liệu tiên tiến. Có vẻ như bong 
bóng bất động sản không phải là vô tận và giá nhà đất sớm muộn sẽ trở lại phù hợp (“The age of big data in real estate, hard to save the sunset industry", 2013). Đó là chìa khóa để phát triển và tiếp thị bất động sản cho các doanh nghiệp bất động sản Trung Quốc sử dụng dữ liệu lớn một cách hiệu quả.

Số lượng dữ liệu khổng lồ với sự đa dạng và phức tạp đó mang lại mô hình doanh thu mới và không gian rộng lớn để phát triển. Trong các ứng dụng hiện tại của dữ liệu lớn, các doanh nghiệp bất động sản bao gồm các nhà phát triển, đại lý và công ty quản lý tài sản đều mở rộng nhiều lĩnh vực kinh doanh toàn diện. Hoạt động phát triển bất động sản, dịch vụ trung gian và quản lý tài sản gắn bó chặt chẽ với nhau.

\subsection{Các úng dụng của dũ liệu lớn trong phát triển thục tế}

Dữ liệu lớn cung cấp hỗ trợ mạnh mẽ để phát triển một cách hợp lý hơn. Nó mang lại lợi ích cho các doanh nghiệp bất động sản khi thực hiện đầu tư đa dạng thông qua việc nhắc nhở dữ liệu về giá trị tiềm năng. Thông tin cá nhân kỹ thuật số và những thay đổi mang tính cách mạng trong cách suy nghĩ khiến các khoản đầu tư đổi mới trở thành cơ hội tăng trưởng doanh thu mới cho các doanh nghiệp kinh doanh trong thời đại dữ liệu lớn.

\section{2. Đầu tu hợp lý và phát triển đa dạng}

Nước ta có 63 tỉnh thành với giá nhà ở khác nhau và nhu cầu đầu tư khác nhau cũng như môi trường tự nhiên đa dạng và tình hình phát triển kinh tế ở các vùng khác nhau.

Nhìn chung, thị trường bất động sản vẫn đang tăng đều, nhưng hiện tượng những khu phố ma nhà trống đã đi chệch hướng nghiêm trọng so với kỳ vọng của các chủ đầu tư. May mắn thay, lịch sử bất động sản đủ lâu để các doanh nghiệp này sở hữu lượng lớn dữ liệu như vị trí địa lý, tình hình phát triển kinh tế, định hướng chính sách quy hoạch đô thị, đầu tư xây dựng, thị trường đất đai cạnh tranh, v.v.

Sử dụng một phương pháp tiên tiến để phân tích dữ liệu lớn, các doanh nghiệp này có thể dự báo nguồn cung và nhu cầu, sau đó định giá khoản đầu tư để đưa ra quyết định sáng suốt. Mặc dù dữ liệu phi cấu trúc này chưa ổn định.

Google có thể là công ty tiên phong trong dự đoán dữ liệu lớn. Trước khi đại dịch cúm tiềm ẩn bùng phát vào năm 2009, google đã nhanh chóng cung cấp các chỉ số chính xác bằng cách phân tích mối quan hệ giữa việc tìm kiếm các từ khóa được thu thập từ năm 2003 đến năm 2008 và các trường hợp thực tế. Điều đó đã giúp CDC của Mỹ có thêm cơ hội. Theo cách tương tự, google ước tính cân bằng cung cầu và dự đoán thành công chỉ số giá trên thị trường bất động sản. Những gì google đã làm chỉ là phân tích dữ liệu được lưu trữ, lập mô hình toán học, thao tác và so sánh.

Google có hiệu quả gấp nhiều lần chính phủ với một phần nhỏ chi phí (Wu \& Brynjolfsson, 2013). Đó là một phần hữu dụng của dữ liệu lớn.

Tài nguyên đất rất quan trọng đối với các doanh nghiệp kinh doanh bất động sản. Dữ liệu lớn cung cấp tiềm năng cho các doanh nghiệp bất động sản tiếp cận thông tin thị trường đất đai rõ ràng. Các doanh nghiệp kinh doanh bất động sản cần coi trọng thị trường đất nền và quan tâm đến xu hướng thị trường. China Vanke Co., Ltd. luôn tập trung vào thị trường dân cư và dữ liệu về tài nguyên đất hầu như đến từ bên thứ ba. Trước tình hình giá đất liên tục leo thang, Vanke phân tích dữ liệu lớn để có được đất trên thị trường thứ cấp, hoặc từ sự chuyển đổi "ba cũ", hoặc đất xây nhà giá rẻ. Sẽ có lợi cho các doanh nghiệp kinh doanh bất động sản khi phân tích dữ liệu lớn về tài nguyên đất để đối phó với giá đất tăng. "Giữ nguyên nơi cư trú, không tích trữ tài sản và không 
tích trữ đất đai” là chiến lược dữ liệu lớn của Vanke (Xishang, 2013).

Ngoài việc phân tích cung - cầu hay mua đất hợp lý, việc ứng dụng dữ liệu lớn vào đầu tư đa dạng trong phạm vi toàn doanh nghiệp cũng mang lại lợi nhuận khủng. Tập đoàn Wanda và Tập đoàn Greenland và một số công ty khác tận dụng cơ hội của dữ liệu lớn để mở rộng hoạt động kinh doanh của họ sang dịch vụ khách sạn và hàng hóa du lịch, mở ra hướng mới về lợi nhuận ngoài thị trường nhà ở. Như Viktor nói, việc tái chế dữ liệu có thể tiết lộ giá trị tiềm năng của nó thay vì giảm giá trị. Ban đầu, dữ liệu lớn không được thu thập để đầu tư đa dạng có thể mang lại thêm lợi nhuận thông qua phân tích sâu.

\section{3. Đầu tư đổi mới}

Trước đây việc phân tích dữ liệu trong việc mua và bán rất hữu ích cho sự phát triển và đầu tư. Tuy nhiên, những doanh nghiệp này đặc biệt là những doanh nghiệp lớn, sở hữu nhìu hơn thế. Dữ liệu về thông tin cá nhân của người mua nhiều hơn đáng kể (tên người mua, hoàn cảnh gia đình, thu nhập tài chính, tỉ lệ thành công mua hàng,...). Ngày càng có nhiều thông tin cá nhân dễ dàng được thu thập do sự phát triển của internet và máy tính trong thời đại dữ liệu lớn phát triển. Rất nhiều thông tin đã từng bị phớt lờ đi như: thói quen, sở thích của người tiêu dùng,... Những dữ liệu này có giá trị tiềm năng rất lớn, nó là cơ hội mới để đột phá và thúc đẩy mô hình bất động sản phát triển nói riêng và nền kinh tế nói chung.

Vanke Group và Fantasia Group, hai trong số những doanh nghiệp kinh doanh bất động sản hàng đầu, cũng đi đầu trong việc ứng dụng dữ liệu lớn. Dựa trên nhu cầu của người tiêu dùng, Fantasia đã lên kế hoạch xây dựng thương mại điện tử cộng đồng một cách sáng tạo, kết hợp người thuê thương mại với khách hàng thông qua ứng dụng trên điện thoại di động. Nắm giữ dữ liệu của hàng triệu người mua nhà, Fantasia có thể thiết lập một nền tảng hiệu quả thuận tiện để tiếp thị. Lợi thế về dữ liệu lớn này sẽ giúp Fantasia đồng thời cải thiện sức mạnh. Ngoài thương mại điện tử cộng đồng, Fantasia còn mở rộng hoạt động kinh doanh dữ liệu lớn dựa trên Internet di động sang các lĩnh vực khác, chẳng hạn như: lĩnh vực tài chính, dịch vụ khách sạn, văn hóa và du lịch.

Việc cải tiến các kỹ thuật xử lý dữ liệu lớn mang lại cơ hội kinh doanh to lớn cho Vanke Group theo cách tương tự. 4,8 triệu chủ sở hữu bất động sản có nghĩa là một số tài sản khổng lồ đối với Vanke. Sau khi xử lý dữ liệu, Vanke đưa ra khái niệm xây dựng các dịch vụ hỗ trợ thành phố, kết hợp hậu cần cộng đồng, dịch vụ y tế và lương hưu với dữ liệu lớn của 4,8 triệu chủ sở hữu bất động sản. Nó sẽ mang lại một cơ hội tuyệt vời ("Recognize the big data, the transition of realty companies needs soft power”, 2013). Đầu tư sáng tạo của Shimao Group đáng chú ý hơn so với Vanke và Fantasia. Như các ý tưởng kinh doanh đã nêu, chủ sở hữu thích kết hợp nhiều tiện ích hơn là một ngôi nhà đơn thuần trong tương lai. Do đó, Shimao đã giới thiệu quản lý kinh doanh "đám mây sức khỏe" cho các chủ sở hữu tài sản của mình để theo dõi sức khỏe và đưa ra ý kiến tư vấn. Phân tích dữ liệu màn hình được thu thập bởi một số thiết bị di động như điện thoại di động và đồng hồ trong thời gian thực, chúng có thể tạo ra lời khuyên cho sức khỏe, phòng ngừa bệnh tật và giúp những chủ sở hữu này giữ gìn sức khỏe hoặc cung cấp cho họ dịch vụ y tế ("Recognize the big data, the transition of realty companies needs soft power”, 2013). Tận dụng lợi thế của dữ liệu lớn, các doanh nghiệp khác như Gold Ground Group và Green Ground Group cũng liên tiếp mở các hoạt động mới như Intelligent City và Cloud Service. Các doanh nghiệp này quan tâm nhiều hơn đến sự thỏa mãn về tinh thần và tâm lý của người tiêu dùng thay vì chỉ đơn thuần là "nơi cư trú". Dịch vụ tốt hơn cho khách hàng quan trọng rất nhiều.

Việc ứng dụng dữ liệu lớn trong đầu tư đổi mới sáng tạo là điều thường thấy tại các doanh nghiệp bất động sản nước ngoài. Trường hợp cổ điển, Windermere Real Estate, phổ biến trong sách giáo khoa đại học của Mỹ. Họ lập kế hoạch cho những người mua tiềm năng với các tuyến 
đường đi làm và chi phí thời gian bằng cách phân tích thông tin từ GPS của gần một trăm triệu người lái xe (Sonka, 2014). Công việc kinh doanh sáng tạo này không chỉ đáp ứng nhu cầu của khách hàng với việc nâng cao chất lượng dịch vụ.

\subsection{Các ứng dụng của dũ liệu lớn trong tiếp thị thục tế}

Để giải quyết những vấn đề này, trên hết, là tiếp thị thành công trong kỷ nguyên dữ liệu lớn. Nguồn dữ liệu rất quan trọng đối với các doanh nghiệp kinh doanh bất động sản để nâng cao năng lực cạnh tranh. Nguồn dữ liệu hoàn hảo và khổng lồ đảm bảo vị trí khách hàng chính xác và hoạt động tiếp thị hiệu quả. Đầu tiên, doanh nghiệp bất động sản có thể thực hiện tiếp thị chính xác dựa vào hệ thống thông tin. Họ có thể xây dựng hệ thống dữ liệu khách hàng dựa trên việc sở hữu dữ liệu lớn để phân loại khách hàng, sau đó trích xuất thông tin hữu ích bằng cách khai thác dữ liệu lớn để tiếp thị chính xác (Juan, 2013).

Ngoài ra, một số doanh nghiệp bất động sản lớn thay đổi hình thức tiếp thị, tích cực chuyển sang thương mại điện tử. Công ty bất động sản Xinfeng (Trung Quốc) đã tạo ra năm hệ thống ứng dụng dữ liệu lớn vào năm 2013. Hệ thống hỗ trợ ra quyết định, mẫu hồ sơ nhà và hệ thống đánh giá tự động là một phần của năm hệ thống đã chạy với hiệu suất cao. Mẫu hồ sơ nhà có thể chọn một số nhà nhất định theo nhu cầu của người dùng. Hệ thống đánh giá tự động có thể đánh giá giá nhà một cách tự động dựa vào xử lí dữ liệu. Khi người dùng nhập dữ liệu về các điều kiện, nó sẽ ước tính giá cả và các thông tin khác như khoản vay và thế chấp hoặc thuế giao dịch. Công ty Xinfeng (Trung Quốc) thực hiện thương mại điện tử thực sự giống như Wanda Group, kết hợp các dịch vụ trực tuyến với các dịch vụ ngoại tuyến.

Các bộ phận kinh doanh ngoại tuyến cũng liên hệ với khách hàng theo thông tin trực tuyến. Mô hình tiếp thị này đòi hỏi kỹ thuật tuyệt vời về thu thập, lưu trữ và phân tích dữ liệu. Vì vậy, các doanh nghiệp bất động sản nên làm chủ công nghệ xử lý dữ liệu cũng như dữ liệu lớn.

\section{Giải pháp và đề xuất}

\subsection{Các vấn đề về dũ liệu lớn và giải pháp}

Dữ liệu lớn bao gồm nhiều thứ hơn là chỉ các con số. Việc thu thập, lưu trữ và xử lý dữ liệu phi cấu trúc khổng lồ này cần công nghệ tiên tiến. Việc tạo ra dữ liệu lớn nhanh chóng và bền vững với mật độ giá trị ngày càng thấp. Đó là một thách thức lớn đối với bất kỳ công ty bất động sản nào trong việc nắm bắt loại thông tin hữu ích từ số lượng lớn của dữ liệu. Một mặt, đưa ra các chiến lược dữ liệu lớn quốc gia và thúc đẩy quá trình nghiên cứu học thuật về dữ liệu lớn và chuyển đổi các thành tựu nghiên cứu thành năng suất thực tế sẽ giúp các tập đoàn bất động sản nâng cao khả năng xử lý dữ liệu lớn. Mặt khác, việc có dữ liệu lớn được xử lý bởi các công ty chuyên nghiệp có thể là một lựa chọn tốt cho các doanh nghiệp bất động sản. Các công ty khác nhau đóng những vai trò khác nhau trong thời đại dữ liệu lớn. Các tập đoàn bất động sản có thể tập trung vào các ứng dụng thông tin để phát triển sâu hơn, giao việc xử lý dữ liệu lớn cho các công ty chuyên nghiệp.

Cần coi trọng giao lưu và hợp tác quốc tế trong thời đại dữ liệu lớn. Trong khi đó, các doanh nghiệp bất động sản cần lưu ý đến khả năng tác động của công nghệ tiên tiến nước ngoài đối với việc ứng dụng dữ liệu lớn. Trong điều kiện này, các công ty trong nước trước hết nên hợp tác với nước ngoài, thúc đẩy quốc tế hóa kinh doanh dữ liệu lớn. Các công ty nước ngoài đóng vai trò trung gian và các công ty trong nước nên giữ quyền sở hữu và giá trị tiềm năng của dữ liệu lớn.

\subsection{Các vấn đề đối với doanh nghiệp bất động sản và giải pháp}

Bất động sản là trụ cột của nền kinh tế thực với một số đặc điểm của nền kinh tế ảo như phức tạp, khả năng di chuyển và rủi ro cao (Siwei, 2009), làm tăng tính mất ổn định trong các ứng 
dụng của dữ liệu lớn. Vì hệ thống nền kinh tế ảo rất nhạy cảm với kỳ vọng, việc công khai và chia sẻ dữ liệu lớn có thể tác động đến nhu cầu đầu tư do những thay đổi về kỳ vọng thực của mọi người. Với kiểu di căn này, sự tác động sẽ làm mất ổn định bất động sản, ảnh hưởng đến sự phát triển kinh tế quốc gia. Do đó, các công ty bất động sản này nên khôn ngoan trong cuộc cách mạng, đồng thời tận dụng cơ hội của dữ liệu lớn để đổi mới.

Kinh doanh toàn diện hơn, phạm vi rộng hơn và quản lý tập thể hơn là xu hướng phát triển hiện nay của các doanh nghiệp bất động sản. Trong điều kiện, hoạt động như thế nào cho hiệu quả cũng là một bài toán lớn về dữ liệu. Các doanh nghiệp bất động sản phải đào tạo người lập kế hoạch kho dữ liệu lớn, tiền bạc, vật chất, thông tin và thực hiện quản lý tích hợp bằng khai thác và phân tích dữ liệu để dự đoán.

\subsection{Kết hợp 3 lĩnh vục Dũ liệu lớn (Big Data) - Trí tuệ nhân tạo (AI) - Internet vạn vật (IOT)}

Hiện tại các doanh nghiệp ở Việt Nam chỉ xem Big Data như là 1 công cụ giúp doanh nghiệp lấy dữ liệu khách hàng. Nhưng chưa thực sự biết cách đi xa hơn để phát triển Big Data này kết hợn với $\mathrm{AI}$ và $\mathrm{IOT}$. Sự kết hợp giữa Big Data, $\mathrm{AI}, \mathrm{IOT}$ sẽ là một bộ ba quyền lực và hữu ích cho các đơn vị quản lý tài sản và bất động sản. Dữ liệu thời gian thực về các hoạt động di chuyển trong phạm vi dự án bất động sản sẽ cho phép ban quản lý tòa nhà điều chỉnh ánh sáng và nhiệt độ phù hợp. Trong một trung tâm thương mại, nhiều dữ liệu sẽ cho phép chủ đầu tư dự án chọn lựa và tìm vị trí phù hợp cho khách thuê tốt hơn.

Lướt web trực tuyến để tìm kiếm bất động sản đã khá phổ biến với các dự án nhà ở và thương mại nhỏ. Môi giới ảo, sử dụng các thuật toán để giúp người mua tìm thấy những gì họ muốn, có thể thay thế các môi giới viên thực hiện nhiều nhiệm vụ, từ đó giải phóng và cho phép họ giải quyết các công việc cần tương tác trực tiếp và mang lại giá trị gia tăng.

AI là một trong những công nghệ cơ sở cho nền tảng đám mây thành phố thông minh của công ty Ping An. Nền tảng này hiện đang được thử nghiệm trên 30 thành phố của Trung Quốc. Tại Thâm Quyến, Ping An đã tạo ra một hệ thống kiểm soát giao thông giảm ùn tắc và tai nạn, và đã tiết kiệm cho các doanh nghiệp nhà nước ở Nam Ninh 129 triệu nhân dân tệ chi phí vốn bằng cách sử dụng quản lý tài chính thông minh.

\section{Kết luận}

Dũ liệu lớn đã trở thành một loại hình tài nguyên chiến lược quan trọng để các doanh nghiệp bất động sản nâng cao năng lực cạnh tranh. Hiện tại, việc ứng dụng dữ liệu lớn vào các doanh nghiệp bất động sản Trung Quốc đã đạt được nhiều thành công. Việc xử lý và phân tích dữ liệu lớn là phù hợp với thực tế, tránh phát triển quá mức và tích cực đối phó với giá đất tăng cho các doanh nghiệp, đồng thời tạo điều kiện cho sự phát triển đa dạng và đầu tư đổi mới. Hơn nữa, các ứng dụng của dữ liệu lớn trong tiếp thị thực đã thúc đẩy doanh số bán hàng thực rất nhiều. Tuy nhiên, do dữ liệu lớn mới bắt đầu nên việc thực hiện trong lĩnh vực này chưa hoàn thiện, đối mặt với nhiều vấn đề như bảo vệ quyền riêng tư, kỹ thuật xử lý dữ liệu và những thách thức xuất phát từ đặc điểm riêng của bất động sản.

Các nghiên cứu sâu hơn có thể tập trung vào ứng dụng cụ thể của dữ liệu lớn, nghiên cứu chi tiết các phương pháp và công nghệ nội bộ. Lý thuyết và thực hành bổ sung cho nhau. Nỗ lực đầy tham vọng trong việc ứng dụng dữ liệu lớn trong các doanh nghiệp bất động sản sẽ làm sâu sắc thêm các nghiên cứu liên quan. Trong khi đó, nghiên cứu khoa học sẽ có lợi cho những thành tựu rực rỡ của các doanh nghiệp bất động sản trong thời đại dữ liệu lớn. 


\section{Tài liệu tham khảo}

Bài nghiên cứu của Danyang Dua, Aihua Lia*, Lingling Zhangb. Central University of Finance and Economics, Xueyuan South Road 39, Haidian District, Beijing,100081, China Management School. University of Chinese Academy of Sciences, Kexueyuan South Road 6, Haidian District, Beijing,100080, China.

Cách thu thập data khách hàng bất động sản hiệu quả thời đại 4.0. (n.d.). Retrieved October 10, 2019, from https://landsoft.com.vn/cach-thu-thap-data-khach-hang-bat-dong-san-hieu-qua-thoi-4$0 /$

Dữ liệu lớn: Chìa khóa giúp nhà đầu tư địa ốc ra quyết định chính xác. (2019). Retrieved May 6, 2019, from https://vneconomy.vn/du-lieu-lon-chia-khoa-giup-nha-dau-tu-dia-oc-ra-quyetdinh-chinh-xac-20190505220030794.htm

Giải pháp nghiên cứu thị trường. (n.d.). Retrieved October 11, 2019, from https://research.batdongsan.com.vn/giaiphap-nghiencuu-thitruongBDS/index.aspx

Juan, Y. (2013). The precise marketing based on big data in the real estate enterprises. Market Weekly, 9, 66-67.

Li, G., \& Xueqi, C. (2012). Research status and scientific thinking of big data. Bulletin of Chinese Academy of Sciences, 27(6), 647-657.

Lohr, S. (2012). The age of big data. Retrieved October 12, 2019, from http://euler.mat.ufrgs.br/ viali/estatistica/estatistica/relacionados/08_Big\%20Data\%20Impac t\%20in\%20the\%20World.pdf

Manyika, J., Chui, M., Brown, B., Bughin, J., Dobbs, R., Roxburgh, C., \& Byers, A. H. (2011). Big data: The next frontier for innovation, competition, and productivity. Retrieved October 13, 2019, from https://www.mckinsey.com/business-functions/mckinsey-digital/our-insights/bigdata-the-next-frontier-for-innovation\#

Mayer-Schönberger, V., \& Cukier, K. (2014). Big data: A revolution that will transform how we live, work, and think. American Journal of Epidemiology, 179(9), 1143-1144.

Quốc hội. (2013a). Hiến pháp nước Cộng hòa xã họi chủ nghĩa Việt Nam [Constitution of the Socialist Republic of Vietnam]. Retrieved October 14, 2019, from https://thuvienphapluat.vn/van-ban/Bo-may-hanh-chinh/Hien-phap-nam-2013-215627.aspx

Quốc hội. (2013b). Luật Đất đai [Land Law]. Retrieved October 15, 2019, from https://thuvienphapluat.vn/van-ban/Bat-dong-san/Luat-dat-dai-2013-215836.aspx

Quốc hội. (2014). Luật Kinh doanh bất động sản [Law on real estate business]. Retrieved October 16, 2019, from https://thuvienphapluat.vn/van-ban/Thuong-mai/Luat-Kinh-doanh-bat-dongsan-2014-259722.aspx

Recognize the big data, the transition of realty companies needs soft power. (2013). Retrieved from http://house.china.com.cn/chongqing/view/688439.htm

Siwei, C. (2009). The fundamentals and research methods of fictitious economy. Management Review, 2l(1), 3-18.

Sonka, S. (2014). Big data and the Ag sector: More than lots of numbers. International Food and Agribusiness Management Review, 17(1), 1-20.

The age of big data in real estate, hard to save the sunset industry. (2013). Retrieved October 17, 2019, from http://news.nb.soufun.com/2013-07-16/10532468_all.html 
Williams, D. (2020). How big data will impact real estate buying, selling and developing. Retrieved October 18, 2019, from https://www.mansionglobal.com/articles/how-big-data-will-impactreal-estate-buying-selling-and-developing-210771

Wu, L., \& Brynjolfsson, E. (2013). The future of prediction: How Google searches foreshadow housing prices and sales. In A. Goldfarb, S. M. Greenstein \& C. E. Tucker (Eds), Economic analysis of the digital economy (pp. 89-118). Chicago, US: University of Chicago Press.

Xishang, W. (2013). The Statement of Vanke: Not the crown, green transformation for the firstmover advantage. Stock Market Trend Analysis Weekly, 13(18). 